\title{
Differences in inflammatory pain in nNOS-, iNOS- and eNOS-deficient mice
}

\author{
Michael Karl Boettger ${ }^{a}$, Nurcan Üceyler ${ }^{\text {a }}$, Marek Zelenka ${ }^{a}$, Angelika Schmitt ${ }^{\mathrm{b}}$, \\ Andreas Reif ${ }^{\mathrm{b}}$, Yong Chen ${ }^{\mathrm{a}}$, Claudia Sommer ${ }^{\mathrm{a}, *}$ \\ a Department of Neurology, Julius-Maximilians-University, Josef-Schneider-Str. 11, 97080 Würzburg, Germany \\ ${ }^{\mathrm{b}}$ Molecular and Clinical Psychobiology, Department of Psychiatry and Psychotherapy, Julius-Maximilians-University Würzburg, \\ Füchsleinstrasse 15, 97080 Würzburg, Germany
}

Received 12 July 2006; received in revised form 28 November 2006; accepted 28 December 2006

Available online 28 March 2007

\begin{abstract}
To assess the relative importance of the isoforms of nitric oxide synthase (NOS) in inflammatory pain, we directly compared pain behaviour and paw thickness after intraplantar injection of complete Freund's adjuvant (CFA) in wild-type (WT) mice and in mice lacking either inducible (iNOS), endothelial (eNOS) or neuronal NOS (nNOS). In mice deficient for nNOS, thermal hyperalgesia was reduced by approximately $50 \%$ compared to wild type mice at 4 and $8 \mathrm{~h}$ after CFA injection, and mechanical hypersensitivity was absent. The only change in pain behaviour in iNOS and eNOS deficient mice compared to WT mice was a more rapid recovery from thermal hyperalgesia. A compensatory up-regulation of nNOS in dorsal root ganglia (DRG) and spinal cords of iNOS and eNOS knockout mice was excluded using RT-PCR. However, an increase of iNOS gene expression was found in spinal cords of eNOS and nNOS deficient mice. To study the downstream effects of nNOS deficiency on DRG neurones, we assessed their immunoreactivity for calcitonin gene-related peptide (CGRP) and cytokines. We found a significant reduction in the CFA induced increase in CGRP immunoreactive neurones as well as in CGRP gene expression in nNOS deficient mice, whereas the percentage of cells immunopositive for tumour necrosis factor- $\alpha$ (TNF- $\alpha$ ) and interleukin-1 $\beta$ (IL-1 $\beta$ ) was unchanged. These results support the proposed role of nNOS in sensitization of DRG neurones, and might indicate that CGRP is involved in this process.

(C) 2007 Published by Elsevier Ltd on behalf of European Federation of Chapters of the International Association for the Study of
\end{abstract} Pain.

Keywords: Hyperalgesia; Allodynia; Behavioural testing; Nitric oxide synthase; Knockout; Calcitonin gene related peptide

\section{Introduction}

Nitric oxide (NO) is involved in sensitization of peripheral and central sensory neurones after noxious stimuli (Meller and Gebhart, 1993). Due to its short half life, the regulation of NO-production mainly depends on the expression of nitric oxide synthases (NOS) and their activity, which is, besides others, regulated by arginine

\footnotetext{
${ }^{*}$ Corresponding author. Tel.: +49931201 24621; fax: +49931201 23697.

E-mail address: sommer@klinik.uni-wuerzburg.de (C. Sommer).
}

and tetrahydrobiopterin (Krumenacker et al., 2004; Tegeder et al., 2006). To date, three isoforms of NOS have been identified. Neuronal NOS (nNOS) is localized in a discrete population of neurones (Bredt et al., 1991) and is dynamically regulated after peripheral inflammation (Herdegen et al., 1994; Wu et al., 1998; Dolan et al., 2003). Inducible NOS (iNOS) is mainly absent in neural tissues under normal conditions, but up-regulated in inflammation (Mungrue et al., 2003), for example in astrocytes in the spinal cord dorsal horn (Maihöfner et al., 2000). Endothelial NOS (eNOS) is present in the brain vasculature (Stanarius et al., 1997) and also in 
astrocytes (Wiencken and Casagrande, 1999). Thus, all three NOS isoforms can act as sources of NO in the CNS after inflammation. The non-selective NOS inhibitor $\mathrm{N}_{\omega}$-nitro-L-arginine methyl ester (L-NAME) reduces thermal hyperalgesia in inflammatory pain models (Semos and Headley, 1994; Osborne and Coderre, 1999), indicating a role of NO in inflammatory pain. Furthermore, several reports indicated beneficial effects of selective blockers for nNOS and iNOS in reducing inflammatory and neuropathic pain, while baseline nociceptive responses remained unaltered (Malmberg and Yaksh, 1993; Sekiguchi et al., 2004; Tao et al., 2004; LaBuda et al., 2006). In order to assess which of the isoforms is relevant in hyperalgesia, studies have been performed on mice lacking iNOS, eNOS or nNOS, but their results have been contradictory (Chu et al., 2005; Gühring et al., 2000; Tao et al., 2003, 2004).

In this report we directly compared, for the first time, the pain-related behaviour and the amount of paw swelling of nNOS-, iNOS- and eNOS-deficient and wild type mice after intraplantar injection of complete Freund's adjuvant (CFA) under identical conditions.

Furthermore, we investigated downstream effects on the expression of the respective other NOS isoforms in the knock-out mice and of calcitonin gene-related peptide (CGRP) in spinal cord and DRG neurones as well as on the proinflammatory cytokines tumour necrosis factor- $\alpha(\mathrm{TNF}-\alpha)$ and interleukin-1 $\beta$ (IL-1 $\beta)$ in DRG.

\section{Materials and methods}

\subsection{Animals}

Behavioural experiments were performed on adult (7-11 months, $22-26 \mathrm{~g}$ body weight) female mice of C57BL/6J background. These included wild type mice ( $n=30,10$ littermate controls for each of the knockout genotypes), mice deficient for iNOS ( $n=10$; Laubach et al., 1995), eNOS ( $n=10$; Huang et al., 1995), and mice deficient for nNOS of 129S4BL/6J background ( $n=9$; The Jackson Laboratory, Bar Harbor, Maine, USA; Huang et al., 1993). For RT-PCR, an additional 10 mice each of wild type, iNOS deficient and eNOS deficient genotype were used. The animals were housed on a light:dark cycle of $14: 10 \mathrm{~h}$ with standard rodent chow and water ad libitum. All experiments were approved by the Bavarian state authorities and carried out in accordance with the European communities Council Directive of 24 November 1986 (86/609/EEC) for the care and use of laboratory animals.

\subsection{Testing protocol}

For baseline testing, mice were examined for withdrawal latencies to heat, withdrawal thresholds to mechanical stimulation with von Frey hairs, and paw thickness (see below) twice before treatment. Under a short ether anaesthesia, animals were injected by an experienced assistant with $20 \mu \mathrm{g}$ of CFA diluted to a volume of $10 \mu \mathrm{l}$ into one dorsal hind paw in the L4 dermatome. Animals were then divided into two groups (each $n=5$ ), one being tested 2, 4, 6 and $8 \mathrm{~h}$ after injection, the other being assessed at 12 and $16 \mathrm{~h}$ after injection.

\subsection{Behavioural tests}

Thermal hyperalgesia was assessed with an algesimeter (Ugo Basile, Comerio, Italy) as described previously (George et al., 2000). After accommodation of the animals to the testing device, three consecutive thermal stimuli were applied to the hind paws with at least a 1min interval between stimulating left and right paws. Means of latencies were calculated and used as a measure of the withdrawal threshold to heat. Mechanical sensitivity was assessed using von Frey hairs with hair values ranging from 1.65 to 5.46 and the up-down method (Chaplan et al., 1994; Dixon, 1965) was applied. The $50 \%$ probability withdrawal threshold (force of the von Frey hair to which an animal reacts in $50 \%$ of the stimuli) was recorded. All behavioural testing was done by observers unaware of the respective genotype. Paw thickness was measured after thermal latencies and mechanical nociceptive thresholds were determined. Here, mice were gently placed in a piece of cloth and, after settling, a calibrated micrometer was used to measure the maximal dorso-ventral thickness of the paw.

\subsection{Immunohistochemistry}

Tissues were obtained immediately after the final testing. Mice were anaesthetized using ether and euthanized. Spinal cords at the levels of L4-L5 and the L4 dorsal root ganglia (DRG) from both sides and thoracic ganglia were removed, embedded into OCT-medium (optimal cutting temperature, TissueTek ${ }^{\circledR}$ ) and snapfrozen in isobutene placed in liquid nitrogen. Cryosections of $10 \mu \mathrm{m}$ were prepared, thaw-mounted on PolyL-Lysin-coated coverslips (Superfrost ${ }^{\mathrm{TM}}$ ) and fixed in $4 \%$ paraformaldehyde for $30 \mathrm{~min}$. Tissues were then blocked for 30 min with $0.3 \% \mathrm{H}_{2} \mathrm{O}_{2}$, diluted in methanol. Sections were incubated over night at $4{ }^{\circ} \mathrm{C}$ with primary antibodies against activating transcription factor 3 (ATF3, Santa Cruz Biotechnology, Santa Cruz, USA), calcitonin gene-related peptide (CGRP, Peninsula Laboratories, San Carlos, USA), tumour necrosis factor- $\alpha$ (TNF- $\alpha$, Linaris, Wertheim, Germany), interleukin-1 $\beta$ (IL-1 $\beta$, Endogen, Woburn, USA) and, as positive controls, Neurofilament-200 (Affiniti, Mamhead, UK) for DRG sections, and glial fibrillary acidic protein (GFAP, Chemicon, Temecula, USA) for spinal cord. 
Corresponding antibody diluents were used as negative controls. On the following day, sections were incubated with biotinylated secondary antibodies (Vector, Burlingame, USA) for $30 \mathrm{~min}$. For signal enhancement, sections were treated with avidin-biotin solution (Vector) for $30 \mathrm{~min}$. Specific antibody binding was visualized using a standard di-amino-benzidine (DAB) peroxidase method. Between all steps sections were washed three times in phosphate buffered saline (PBS).

\subsection{Image analysis}

For each genotype, sections of $10 \mathrm{DRG}$, ipsi- and contralateral to CFA-injection, and of three thoracic ganglia were analysed by light microscopy (Axiophot, Zeiss, Jena, Germany). After sections were photographed, an average of 290 (range: 220-416 in four sections per specimen) neuronal profiles were counted for each DRG. Cell sizes (area of profile in $\mu \mathrm{m}^{2}$ ) were measured using ImageProPlus software (Version 4.0, Media Cybernetics, USA). Cells were considered immuno-positive when the staining signal was clearly above the background level. For size standardization, only cells with a visible nucleus were considered for analysis. Analysis was performed by an observer masked as to treatment and genotype. For some specimens, sections were analysed by a second masked observer, showing an overall inter-observer variability of less than $8 \%$.

For spinal cord, two sections of the lumbar region (L4/L5) of each animal were assessed. The obtained immunohistochemical signal was speckled and covered the superficial dorsal horn of the spinal cords. Intensity of staining was measured after transferring photographed sections into gray scale mode and defining gray scale values (scale $0-255$ ) at 10 different sites of laminae I and II using ImageProPlus software. To correct for background activity, activity measured in the ventral horn of the identical spinal cord was subtracted.

\section{6. $R T-P C R$}

Fresh spinal cord specimens at the L4/L5 level and bilateral L4 and L5 DRG were harvested from wild type, nNOS deficient, iNOS deficient and eNOS deficient mice $24 \mathrm{~h}$ after injection of CFA or normal saline ( $n=5$ for each genotype and treatment). Tissue homogenization and RNA isolation were performed as described previously (Kleinschnitz et al., 2004). In brief, total RNA from each tissue was prepared using the TRIzol reagent ${ }^{\circledR}$ (Invitrogen, Germany) and was quantified spectrophotometrically. Tissues were homogenized using a Polytron ${ }^{\circledR}$ homogenizer (Kinematica, Germany) at $39.000 \mathrm{rpm}$ for $25 \mathrm{~s}$.

Relative nNOS-, iNOS-, eNOS-, and CGRP-mRNA levels were quantified with real-time PCR using the fluorescent TaqMan technology. About $500 \mathrm{ng}$ of total
RNA were reverse transcribed (TaqMan Reverse Transcription Reagents, Applied Biosystems, Germany) using random hexamers.

PCR primers and probes specific for murine nNOS, iNOS and eNOS as well as CGRP and 18s rRNA were obtained as TaqMan Predeveloped Assay Reagents for gene expression (Applied Biosystems, Germany). 18s rRNA was used as an endogenous control to normalize to the amount of sample RNA. PCR was performed with equal amounts of cDNA in the GeneAmp 7700 sequence detection system (Applied Biosystems, Germany) using TaqMan Universal PCR Master Mix (Applied Biosystems, Germany). Reactions (total volume $50 \mu \mathrm{l}$ ) were incubated at $50{ }^{\circ} \mathrm{C}$ for $2 \mathrm{~min}$, at $95^{\circ} \mathrm{C}$ for $10 \mathrm{~min}$ followed by 40 cycles of $15 \mathrm{~s}$ at $95^{\circ} \mathrm{C}$ and $1 \mathrm{~min}$ at $60^{\circ} \mathrm{C}$. Water controls were included to ensure specificity. Each sample was measured in triplicate and data points were examined for integrity by analysis of the amplification plot.

The comparative $\mathrm{Ct}$ method was used for relative quantification of gene expression (Winer et al., 1999). The amount of nNOS mRNA, normalized to the endogenous control (18s rRNA) and relative to a calibrator (tissue from healthy animals), is given by $2^{-\Delta \Delta \mathrm{Ct}}$, with $\mathrm{Ct}$ indicating the cycle number at which the fluorescence signal of the PCR product crosses an arbitrary threshold set within the exponential phase of the PCR, and $\Delta \Delta \mathrm{Ct}=\left[\left(\mathrm{Ct}_{\text {target(unknown sample) }}-\right.\right.$ $\mathrm{Ct}_{\text {end.control(unknown }}$ sample) $\left.)\right]-\quad\left[\left(\mathrm{Ct}_{\text {target(calibrator sample) }}\right.\right.$ $\left.\left.-\mathrm{Ct}_{\text {end.control(calibrator sample) }}\right)\right]$.

\subsection{Data analysis}

Data obtained from behavioural testing were compared using Mann-Whitney ( $U$-) tests and underwent Bonferroni correction because of multiple testing. Values obtained from all wild type control animals were pooled for statistical analysis. Immunohistochemical data were tested for statistical significance using twosided $t$-tests, as they showed normal distribution according to the Kolmogoroff-Smirnoff test. For data from RT-PCR, Mann-Whitney ( $U$-) tests with Bonferroni correction were applied. Statistical analysis was performed using SPSS (Version 11.5, SPSS, Chicago, IL). Data are presented as mean \pm standard deviation (SD).

\section{Results}

\section{1. nNOS deficient mice have reduced thermal} hyperalgesia and lack of mechanical allodynia after CFA injection

Baseline values (before CFA injection) were not different between genotypes. Thermal withdrawal latencies were approximately $10 \mathrm{~s}$ and withdrawal thresholds to 
von Frey hairs were approximately $0.6 \mathrm{~g}$. Paw thickness was generally $2 \mathrm{~mm}$ before injection.

Wild type mice showed reduced withdrawal thresholds for thermal and mechanical stimuli in the CFA injected paw and developed paw swelling, consistent with previous reports on pain-related behaviour in a CFA model (Iadarola et al., 1988; Hylden et al., 1989; Ren et al., 1992).

In mice lacking nNOS, thermal hyperalgesia was present, but was significantly reduced compared to wild-type mice at 4 and $8 \mathrm{~h}$ after CFA-injection (Fig. 1A). Withdrawal thresholds to von Frey hairs were significantly less reduced in CFA injected nNOS-deficient mice compared to wild type mice at all time points measured, and were not different from baseline, indicat- ing lack of mechanical allodynia (Fig. 1B). Paw thickness did not differ between wild-type mice and mice lacking nNOS (see Fig. 1C).

In mice lacking iNOS, withdrawal latencies to heat were reduced early after CFA-injection, but were significantly longer than those in wild-type mice at 8 and $12 \mathrm{~h}$, indicating reduced thermal hyperalgesia (Fig. 1D). Except for an increased mechanical allodynia after $2 \mathrm{~h}$ in iNOS deficient mice, there was no difference between groups in response to von Frey hair stimulation (Fig. 1E). Paw swelling was significantly reduced in iNOS deficient mice at several time points after CFA (Fig. 1F).

Like iNOS deficient mice, mice lacking eNOS had a more rapid recovery from thermal hyperalgesia than
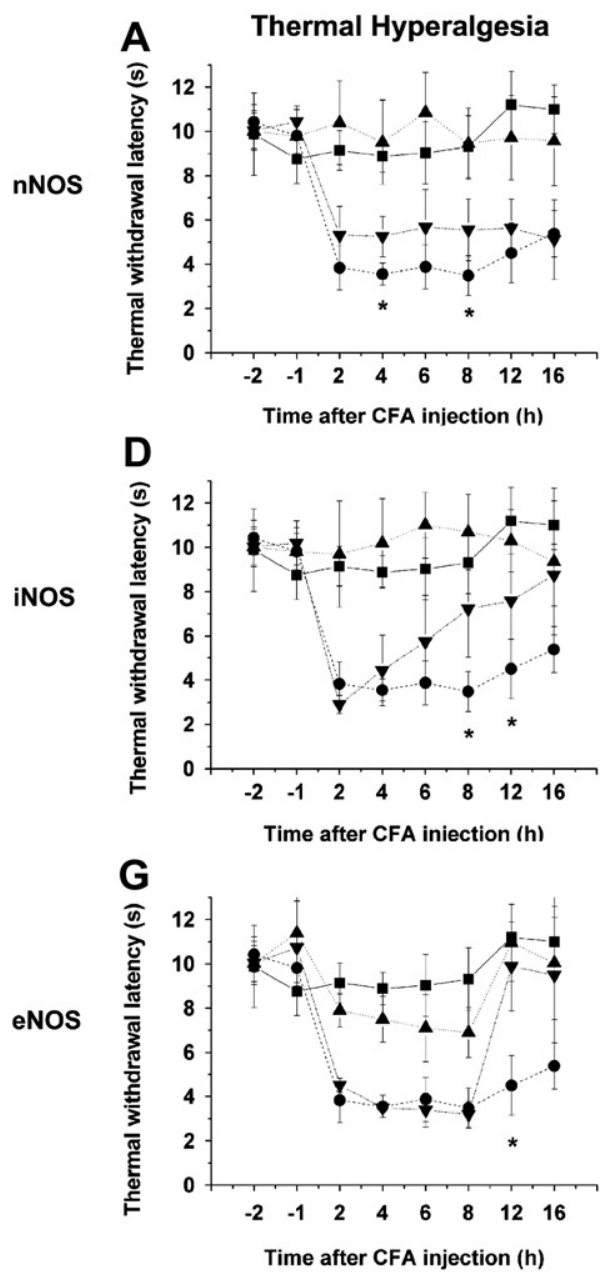
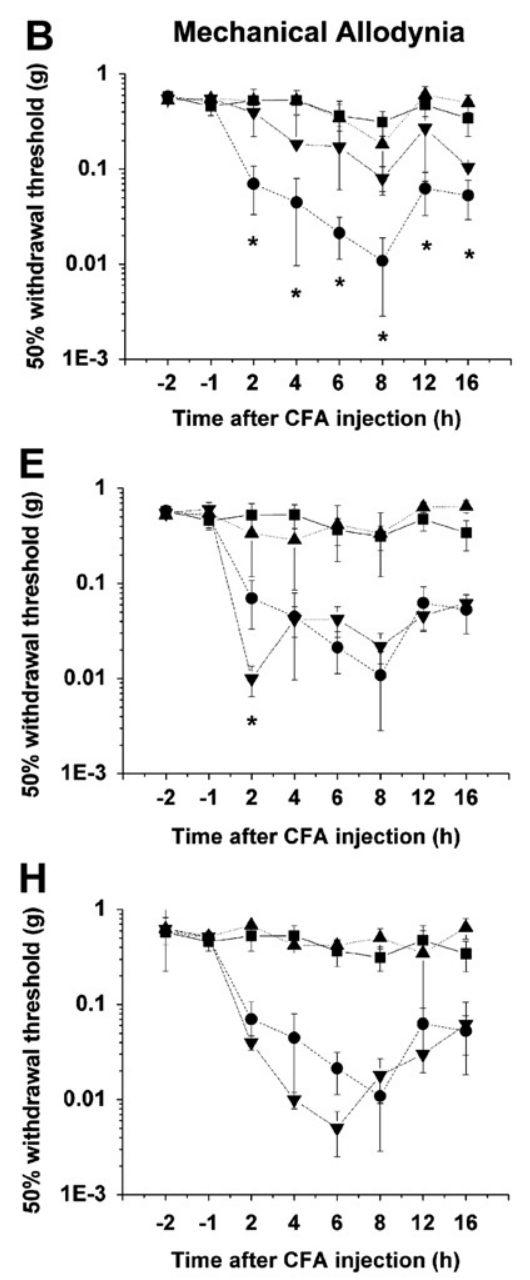
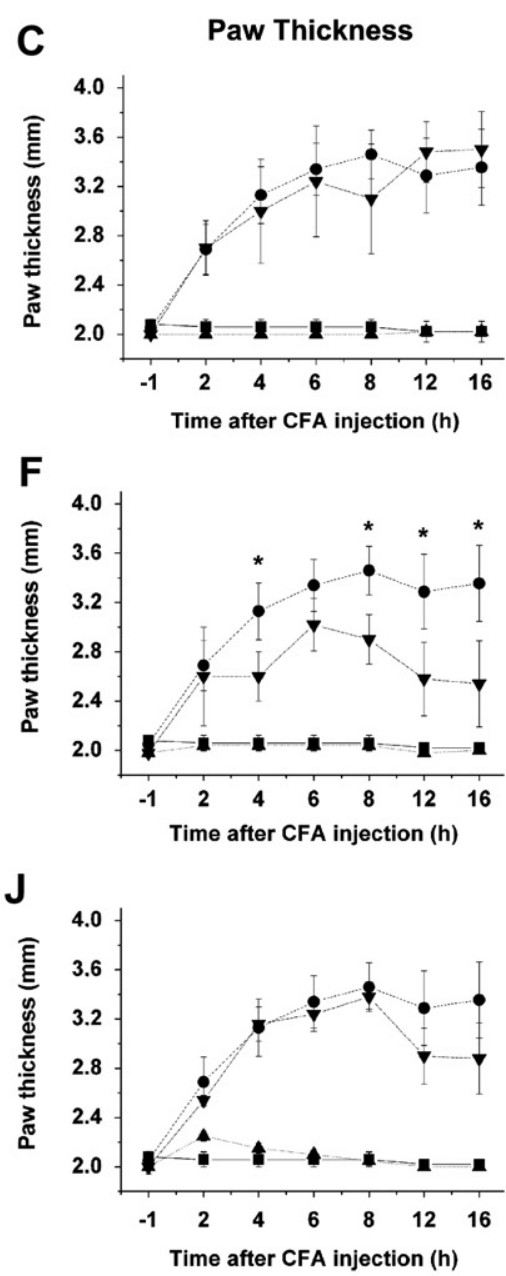

-Wild type contralateral side - Wild type CFA-injected side $\Delta$ Knock out contralateral side Knock out CFA-injected side

Fig. 1. A, D, G. Paw withdrawal latencies in seconds as a measure for thermal hyperalgesia related to time in hours after CFA injection for wild type mice compared to nNOS- (A), iNOS- (D) and eNOS- (G) deficient mice. Panels B, E and H present the force needed for flexion in $\mathrm{g}$ as a measure for mechanical allodynia related to time after CFA injection, again comparing wild type mice with mice deficient for nNOS (B), iNOS (E) and eNOS (H). C, F, J. Paw thickness in mm as a measure for swelling after CFA injection is presented for mice lacking nNOS (C), iNOS (F) and eNOS (J), again compared to wild type mice. Data presented as mean $\pm \mathrm{SD} .{ }^{*} p<0.05$. 
wild-type mice (Fig. 1G). Mechanical allodynia did not differ to wild-type mice (Fig. 1H) and. there was no difference in paw thickness after CFA injection compared to wild type mice (Fig. 1J).

\subsection{Calcitonin gene related peptide (CGRP), but not cytokine immunoreactivity, is lower in DRG neurones of CFA treated nNOS deficient mice}

Mainly small and medium sized DRG neurones showed a dense cytoplasmic signal for CGRP (Fig. 2A and $\mathrm{B}$ ). In wild type mice CFA injection increased the ratio of CGRP immunopositive cells from $37 \%$ to $47 \%$, with a generalized increase of immuno-positive neurones of all sizes. CGRP immunoreactivity remained unchanged in mice deficient for nNOS (Fig. 2C). RTPCR analysis further revealed an increase of CGRPmRNA in DRG of CFA injected wild type mice $(2.3 \pm 0.6$; controls: $1.0 \pm 0.5, p<0.014)$, but not in DRG of nNOS $(1.0 \pm 0.8)$, iNOS $(1.5 \pm 0.4)$ or eNOS deficient mice $(0.3 \pm 0.3)$. In thoracic ganglia which were examined as controls there was no change in CGRP immunoreactivity after CFA in either wild type or nNOS deficient mice (not shown).

In the spinal cord, laminae I and II of the superficial dorsal were densely stained for CGRP (Fig. 3). Signals as assessed using densitometry did not differ significantly between CFA-injected and contralateral side nor between wild type animals and mice deficient for nNOS (not shown). mRNA for CGRP did not significantly differ between in spinal cords of wild type mice and any NOS deficient mice (not shown).

About $44.1 \pm 6.3 \%$ of DRG neurones showed dense cytoplasmic staining for TNF- $\alpha$ in wild type controls. After CFA, this ratio was slightly increased to $47.3 \pm 8.6 \%$ (n.s.). In mice lacking nNOS, $41.6 \pm 5.7 \%$ of neurones were immunoreactive for TNF- $\alpha$ before, and $49.3 \pm 11.1 \%$ after CFA injection (n.s.).

About $54.3 \pm 6.7 \%$ of DRG neurones from wild type controls as compared to $61.2 \pm 9.9 \%$ in nNOS deficient mice showed cytoplasmic immunoreactivity for IL-1 $\beta$ $(p=0.08)$. After CFA injection, ratios remained unaltered with $57.3 \pm 3.1 \%$ for wild type and $58.6 \pm 7.6 \%$ for $\mathrm{nNOS}$ deficient mice.

ATF3 immunostaining was used to investigate whether the injection of CFA induced neuronal injury and to quantify possible cytotoxic effects of NO. ATF3 immunohistochemistry resulted in dense nuclear staining in a very small subset of DRG neurones on the CFA-injected sides. An average of $1.9 \pm 1.0 \%$ of cells was immunoreactive for ATF3 on the CFAinjected side as compared to $0.3 \pm 0.8 \%$ on the contralateral side (n.s.). There was no significant difference between mice deficient for nNOS, iNOS, eNOS or wild type mice (data not shown).
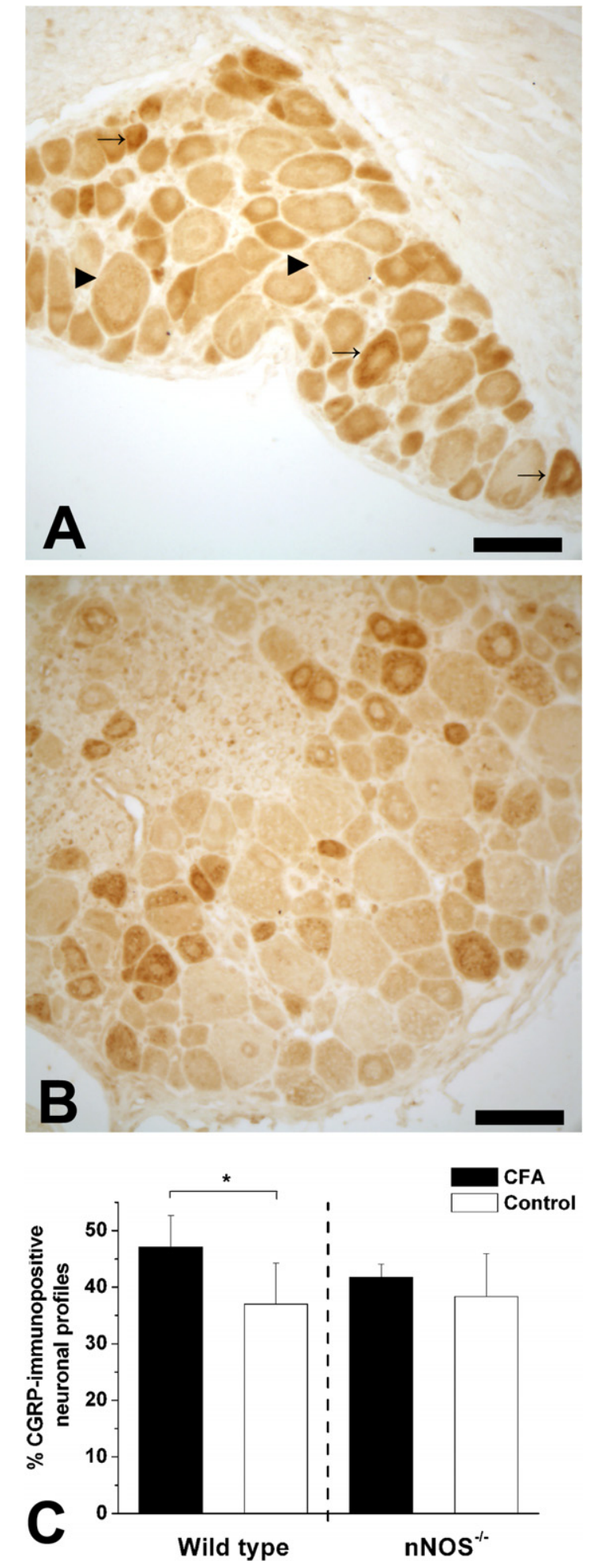

Fig. 2. Representative sections of dorsal root ganglia with mainly small and medium sized neurons labelled for CGRP from wild type (A) and nNOS deficient mice (B) on the side of CFA injection. The ratio of cells immunopositive for CGRP was mildly increased in wild type mice after CFA injection, but remained unchanged in mice lacking nNOS (C). Examples for neuronal profiles considered immunopositive $(\rightarrow)$ and immunonegative $(\nabla)$. Scale bars $=100 \mu \mathrm{m}$. Data in $(\mathrm{C})$ presented as mean \pm SD. ${ }^{*} p<0.05$. 

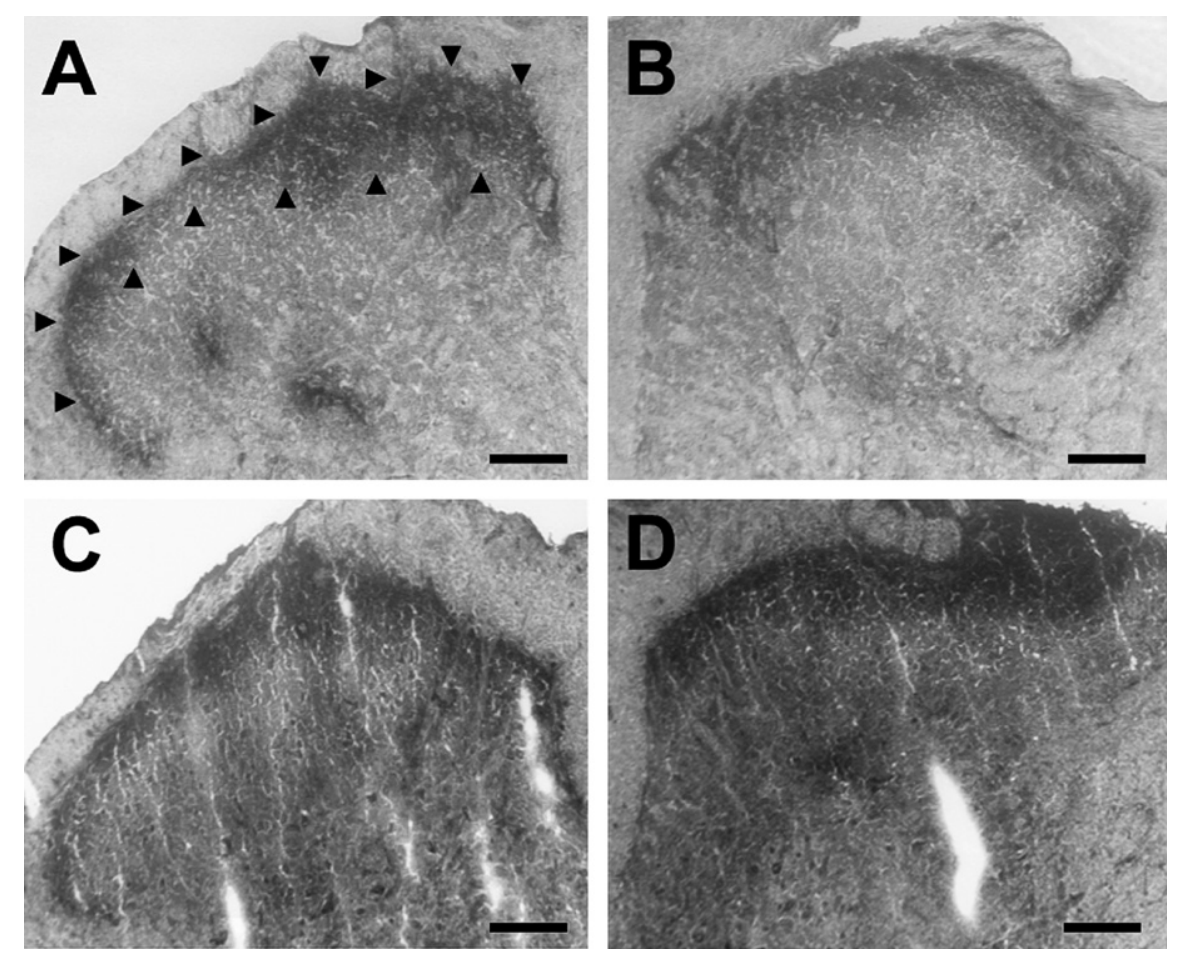

Fig. 3. Dense staining of the superficial dorsal horn (lamina I and II, indicated by arrowheads in A as an example) of spinal cords labeled with antibodies specific for CGRP in wild type (A, B) and nNOS deficient mice (C, D) on the side of CFA injection (A, C) and on the contralateral side (B, D). Images were transformed to gray scale for image analysis, which revealed no difference between CFA-injected and contralateral sides. Scale bars $=100 \mu \mathrm{m}$.

\subsection{Lack of eNOS may be partially compensated by} upregulation of $i N O S$, but not of nNOS, in the spinal cord

Since mice deficient for eNOS and iNOS did not show major behavioural differences to wild type mice after CFA injection, we speculated that this might be caused by compensatory upregulation of the remaining NOS isoforms. We therefore measured relative gene expression of the non-knocked out isoforms in DRG and spinal cords of nNOS, eNOS and iNOS deficient mice. When comparing DRG specimens obtained from nNOS-, eNOS- or iNOS-deficient mice at $24 \mathrm{~h}$ after injection of CFA to wild type controls, relative gene expression of none of the different NOS isoforms was significantly altered (see Table 1a). Tissues from the side contralateral to injection of CFA also showed no differences in NOS mRNA levels (data not shown).

In spinal cord specimens, relative gene expression of iNOS was significantly increased in nNOS and eNOS deficient mice, while none of the other isoforms significantly differed from wild type animals in any genotype (see Table 1b).

\section{Discussion}

Comparing pain behaviour after CFA injection in eNOS-, iNOS-, and nNOS-deficient mice under identical

Table 1

Relative gene expression of NOS isoforms in nNOS, iNOS and eNOS deficient mice

\begin{tabular}{lllll}
\hline & Wild type & $\mathrm{nNOS}^{-/-}$ & $\mathrm{iNOS}^{-/-}$ & $\mathrm{eNOS}^{-/-}$ \\
\hline (a) DRG & & & & \\
nNOS & $1.0 \pm 0.2$ & - & $1.5 \pm 0.6$ (n.s.) & $0.6 \pm 1.7$ (n.s.) \\
iNOS & $1.1 \pm 0.7$ & $1.0 \pm 0.8$ (n.s.) & - & $1.1 \pm 0.7$ (n.s.) \\
eNOS & $1.1 \pm 0.5$ & $0.9 \pm 0.4$ (n.s.) & & - \\
(b) Spinal cord & & & $1.3 \pm 0.4$ (n.s.) & \\
nNOS & $1.0 \pm 0.3$ & - & - & $0.5 \pm 0.4$ (n.s.) \\
iNOS & $1.1 \pm 0.7$ & $3.5 \pm 1.4(p<0.009)$ & $2.7 \pm 0.8$ (n.s.) & $-1.0 \pm(p<0.008)$ \\
eNOS & $1.0 \pm 0.3$ & $1.8 \pm 0.6$ (n.s.) & - \\
\hline
\end{tabular}

Relative gene expression of NOS isoforms in DRG (A) and spinal cords (B) of mice deficient for nNOS, iNOS and eNOS (nNOS ${ }^{-/-}$, iNOS ${ }^{-/-}$, $\mathrm{eNOS}^{-1-}$ ) $24 \mathrm{~h}$ after CFA injection as compared to wild type controls. n.s., not significant. 
conditions, we show that only nNOS-deficient mice have a significant reduction in pain behaviour, whereas we found no major differences to wild type mice in the other genotypes. In addition to the recently described attenuation of mechanical allodynia (Chu et al., 2005), our experiments also revealed a reduction of thermal hyperalgesia in nNOS-deficient mice. Since this reduction was present at 4 and $8 \mathrm{~h}$ after injection of CFA, it indicates a possible role for nNOS in hypersensitivity to heat in early stages of inflammation.

The changes in pain responses we found in mice deficient of eNOS and iNOS were less pronounced. This is in accordance with the finding of an increase in nNOS but not in the other NOS isoforms in mouse spinal cord after CFA (Chu et al., 2005). Pain behaviour in iNOS deficient mice has been investigated previously, with variable results. Gühring and coworkers reported a moderate decrease in early thermal hyperalgesia for iNOS deficient mice in a zymosan model (Gühring et al., 2000). Tao et al. (2003) did not find any difference in thermal hyperalgesia in mice lacking iNOS in a carrageenan-induced inflammatory pain model. In the present study, CFA induced hyperalgesia was only reduced during the recovery phase. One possible explanation for these discrepant findings may be the different time courses of the inflammatory models used. While zymosan injection leads to a rapid onset of symptoms in the first minutes (Meller and Gebhardt, 1997), injection of CFA or carrageenan produces a prolonged effect, with onset of symptoms within hours (Hargreaves et al., 1988; Ren et al., 1992). It is possible that NO has a major effect at the onset of the zymosan model and only later in the development of the CFA or carrageenan model, although this has not been directly experimentally assessed. In addition, the immune response induced by the different agents that are used in different inflammatory pain models might differ significantly.

After a sciatic nerve lesion (chronic constrictive nerve injury), iNOS deficient mice had a delayed development of thermal hyperalgesia (Levy et al., 2001). Although this may in part be due to the reduced NO production directly, it was concomitant with delayed Wallerian degeneration. Therefore, in the nerve injury model, the delay in pain-related behaviour could also be explained by an effect on nerve degeneration.

In our study, the major finding in mice lacking iNOS was a reduction in paw swelling after CFA. Paw swelling did not differ from wild type mice initially, but was significantly decreased at $4 \mathrm{~h}$, paralleled by a significant reduction of thermal hyperalgesia being detectable from $8 \mathrm{~h}$ after CFA injection. Thus, in addition to pain, another cardinal sign of inflammation, swelling, is reduced. With iNOS being strongly expressed in macrophages and neutrophils (Chabrier et al., 1999) and due to its immunomodulatory (Kahl et al., 2003) and pro- inflammatory function (Tinker et al., 2003), these findings might indicate a decreased NO production at the actual site of inflammation. A recent study examining selective iNOS-inhibitors found a significant reduction of pain behaviour in different inflammatory and neuropathic pain models (LaBuda et al., 2006). In the context of our findings, these effects might be secondary to a reduction of the inflammatory response with lower amounts of inflammatory mediators being released, thus leading to a diminished peripheral sensitization of nociceptors.

After nerve injury, eNOS is increased in DRG neurones and in injured axons and was thus suggested to play a role in nerve injury induced hyperalgesia (Levy et al., 2000). In our experiments using eNOS deficient mice, we could neither find a difference for mechanical allodynia, nor for paw thickness, but - similar to mice lacking iNOS - a trend towards an increase of paw withdrawal latencies after thermal stimulation (i.e. reduced thermal hyperalgesia) at late testing points, after 12 and $16 \mathrm{~h}$. Apart from the mechanisms discussed above, the cause for a less significant reduction of pain behaviour in eNOS- and iNOS-deficient mice as compared to animals lacking nNOS might be a compensatory up-regulation of nNOS in these animals, which might restore NOS function and thus sensitization at the spinal level. For instance, in carrageenaninduced inflammation, spinal eNOS protein was increased in nNOS deficient mice, thus partly compensating the decrease of $\mathrm{Ca}^{2+} /$ calmodulin dependent NOS activity on the spinal level (Tao et al., 2004). However, as we can show here, amounts of nNOS mRNA were not increased in eNOS- and iNOS-deficient mice in dorsal root ganglia and spinal cord. Still, this does not rule out an increase in nNOS protein synthesis or activity, which might still account for the remaining behavioural changes seen in these animals. Furthermore, when looking at gene expression for iNOS in the spinal cords of nNOS and eNOS deficient animals, we could find a significant increase. In the case of eNOS deficient mice, this might in part explain the lack of change in pain-related behaviour with iNOS possibly compensating eNOS function. Yet, this upregulation does not seem to affect reduced nociception due to nNOS deficiency. One possible reason for this discrepancy might be the actual site of NO production. While immunoreactivity for eNOS is limited to the endothelium and astrocytes and for iNOS to the lining of the central canal, but also astrocytes in the spinal cord (Wiencken and Casagrande, 1999; Maihöfner et al., 2000; Ruscheweyh et al., 2006), nNOS is mainly expressed in neuronal structures (Bredt et al., 1991; Herdegen et al., 1994). Hence, due to the overlap in expression, iNOS is more likely to be capable of compensating the deficiency of eNOS than of nNOS. 
Several mechanisms have been postulated by which NO leads to neuronal sensitization, among them the induction of spontaneous activity in DRG neurones (Wiesenfeld-Hallin et al., 1993) and the stimulation of prostaglandin synthesis (Gühring et al., 2000). Another mechanism by which NO may further add to sensitization is the activation of neighbouring cells with an increase in their neuropeptide (Garry et al., 2000), cytokine (Holguin et al., 2004) and amino acid release (Fujita et al., 2004). Thus, in states of decreased NO production one would expect an attenuated increase of these substances following inflammation. Accordingly, we found that the increase in CGRP-immunopositive DRG neurones as well as CGRP-mRNA that was seen in wild type mice on the side of CFA injection was missing in mice lacking nNOS. Thus, our data add to the assumption that $\mathrm{NO}$ induces CGRP expression in DRG. However, conclusions on the role of this finding on hyperalgesia are limited by the finding that also in mice with a deficiency for the other NOS isoforms the CFA-induced increase of CGRP mRNA in DRG was absent, although no changes in pain-related behaviour were obvious in these animals.

In addition to a direct role of $\mathrm{NO}$ as a neurotransmitter, increased concentrations of NO can further lead to direct neuronal cell damage (Minc-Golomb et al., 1994). As damaged DRG neurones are liable to change their immunohistochemical properties, it is important to control for neuronal injury. Using immuno-labelling for ATF3, a marker for injured neurones (Tsujino et al., 2000), we found no difference between wild type mice and animals lacking nNOS, eNOS or iNOS. The ratio of ATF3 positive neurones was slightly higher on the CFA sides than on the contralateral sides, but differences did not reach significance. Further, the number of ATF3 immunopositive cells is too small as to account for injury-induced changes after CFA injection or for behavioural differences between genotypes.

Immunoreactivity for TNF- $\alpha$ and IL- $1 \beta$ was apparent in approximately $45 \%$ and $60 \%$ of DRG neurones, respectively, which is well in line with previous reports (Copray et al., 2001; Schäfers et al., 2003). However, there were no differences between wild type and nNOS deficient mice, indicating that this postulated downstream mechanism, i.e. an increase in cytokine expression in inflammation as shown elsewhere (Holguin et al., 2004), is not affected in our model.

In conclusion, our data add to the concept that nNOS is the major NOS isoform in spinal sensitization after noxious stimuli. Furthermore, the regulation of CGRP expression in peptidergic DRG neurones may be an additional factor in nNOS mediated hyperalgesia. iNOS plays an important role at the site of inflammation, with its depletion leading to decreased extravasation-induced paw swelling.

\section{Acknowledgements}

The authors are indebted to Lydia Biko and Barbara Dekant for excellent technical assistance and to K.V. Toyka, MD, for critical reading of the manuscript and helpful suggestions. Further, the authors thank Paula Sherman, University of North Carolina, USA, for the kind supply with iNOS deficient animals and Paul L. Huang for eNOS deficient mice.

\section{References}

Bredt DS, Glatt CE, Hwang PM, Fotuhi M, Dawson TM, Snyder SH. Nitric oxide synthase protein and mRNA are discretely localized in neuronal populations of the mammalian CNS together with NADPH diaphorase. Neuron 1991;7:615-24.

Chabrier PE, Demerle-Pallardy C, Auguet M. Nitric oxide synthases: targets for therapeutic strategies in neurological diseases. Cell Mol Life Sci 1999;55:1029-35.

Chaplan SR, Bach FW, Pogrel JW, Chung JM, Yaksh TL. Quantitative assessment of tactile allodynia in the rat paw. J Neurosci Meth 1994;53:55-63.

Chu YC, Guan Y, Skinner J, Raja SN, Johns RA, Tao YX. Effect of genetic knockout or pharmacologic inhibition of neuronal nitric oxide synthase on complete Freund's adjuvant-induced persistent pain. Pain 2005;119:113-23.

Copray JCVM, Mantingh I, Brouwer N, Biber K, Küst BM, Liem RSB, et al. Expression of interleukin-1 beta beta in rat dorsal root ganglia. J Neuroimmunol 2001;118:203-11.

Dixon W. The up-and-down method for small samples. J Am Stat Assoc 1965;60:967-78.

Dolan S, Kelly JG, Huan M, Nolan AM. Transient up-regulation of spinal cyclooxygenase-2 and neuronal nitric oxide synthase following surgical inflammation. Anaesthesiology 2003;98:170-80.

Fujita T, Kamisaki Y, Yonehara N. Nitric oxide-induced increase of excitatory amino acid levels in the trigeminal nucleus caudalis of the rat with tactile hypersensitivity evoked by the loose-ligation of the inferior alveolar nerves. J Neurochem 2004;91:558-67.

Garry MG, Walton LP, Davis MA. Capsaicin-evoked release of immunoreactive calcitonin gene-related peptide from the spinal cord is mediated by nitric oxide but not by cyclic GMP. Brain Res 2000;861:208-19.

George A, Marziniak M, Schäfers M, Toyka KV, Sommer C. Thalidomide treatment in chronic constrictive neuropathy decreases endoneurial tumour necrosis factor-alpha, increases interleukin-10 and has long-term effects on spinal cord dorsal horn met-enkephalin. Pain 2000;88:267-75.

Gühring H, Görig M, Ates M, Ovidiu C, Zeilhofer HU, Pahl A, et al. Suppressed injury-induced rise in spinal prostaglandin E2 production and reduced early thermal hyperalgesia in iNOS-deficient mice. J Neurosci 2000;20:6714-20.

Hargreaves K, Dubner R, Brown F, Flores C, Joris J. A new and sensitive method for measuring thermal nociception in cutaneous hyperalgesia. Pain 1988;32:77-88.

Herdegen T, Rudiger S, Mayer B, Bravo R, Zimmermann M. Expression of nitric oxide synthase and colocalization with jun, fos and krox transcription factors in spinal cord neurones following noxiuos stimulation of the rat hindpaw. Mol Brain Res 1994;22:245-58.

Holguin A, O'Connor KA, Biedenkapp J, Campisi J, Wieseler-Frank J, Milligan ED, et al. HIV-1 gp120 stimulates proinflammatory cytokine-mediated pain facilitation via activation of nitric oxide synthase-I (nNOS). Pain 2004;110:517-30. 
Huang PL, Dawson TM, Bredt DS, Snyder SH, Fishman MC. Targeted disruption of the neuronal nitric oxide synthase gene. Cell 1993;75:1273-86.

Huang PL, Huang Z, Mashimo H, Bloch KD, Moskowitz MA, Bevan JA, et al. Hypertension in mice lacking the gene for endothelial nitric oxide synthase. Nature 1995;377:239-42.

Hylden JLK, Nahin RL, Traub RJ, Dubner R. Expansion of receptive fields of spinal lamina I projection neurones in rats with unilateral adjuvant-induced inflammation: the contribution of dorsal horn mechanisms. Pain 1989;37:229-43.

Iadarola MJ, Brady LS, Draisci G, Dubner R. Enhancement of dynorphin gene expression in spinal cord following experimental inflammation: stimulus specificity, behavioral parameters and opioid receptor binding. Pain 1988;35:313-26.

Kahl KG, Zielasek J, Uttenthal LO, Rodrigo J, Toyka KV, Schmidt $\mathrm{HH}$. Protective role of the cytokine-inducible isoform of nitric oxide synthase induction and nitrosative stress in experimental autoimmune encephalomyelitis of the DA rat. J Neurosci Res 2003;73:198-205.

Kleinschnitz C, Brinkhoff J, Zelenka M, Sommer C, Stoll G. The extent of cytokine induction in peripheral nerve lesions depends on the mode of injury and NMDA signalling. J Neuroimmunol 2004; 149:77-83.

Krumenacker JS, Hanafy KA, Murad F. Regulation of nitric oxide and guanylyl cyclase. Brain Res Bull 2004;62:505-15.

LaBuda CJ, Koblish M, Tuthill P, Dolle RE, Little PJ. Antinociceptive activity of the selective iNOS inhibitor AR-C102222 in rodent models of inflammatory, neuropathic and post-operative pain. Eur J Pain 2006;10:505-12.

Laubach VE, Shesely EG, Smithies O, Sherman PA. Mice lacking inducible nitric oxide synthase are not resistant to lipopolysaccharide-induced death. Proc Natl Acad Sci USA 1995;92:10688-92.

Levy D, Tal M, Hoke A, Zochodne DW. Transient action of the endothelial constitutive nitric oxide synthase (ecNOS) mediates the development of thermal hypersensitivity following peripheral nerve injury. Eur J Neurosci 2000;12:2323-32.

Levy D, Kubes P, Zochodne DW. Delayed peripheral nerve degeneration, regeneration, and pain in mica lacking inducible nitric oxide synthase. J Neuropathol Exp Neurol 2001;60:411-21.

Maihöfner C, Euchenhofer C, Tegeder I, Beck KF, Pfeilschifter J, Geisslinger G. Regulation and immunohistochemical localization of nitric oxide synthases and soluble guanylyl cyclase in mouse spinal cord following nociceptive stimulation. Neurosci Lett 2000;290:71-5.

Malmberg AB, Yaksh TL. Spinal nitric oxide synthesis inhibition blocks NMDA-induced thermal hyperalgesia and produces antinociception in the formalin test in rats. Pain 1993;54:291-300.

Meller ST, Gebhart GF. Nitric oxide (NO) and nociceptive processing in the spinal cord. Pain 1993;52:127-36.

Meller ST, Gebhardt GF. Intraplantar zymosan as a reliable, quantifiable model of thermal and mechanical hyperalgesia in the rat. Eur J Pain 1997;1:43-52.

Minc-Golomb C, Tsarfaty I, Schwartz JP. Expression of nitric oxide synthase by neurons following exposure to endotoxin and cytokine. Br J Pharmacol 1994;112:720-2.

Mungrue IN, Bredt DS, Stewart DJ, Husain M. From molecules to mammals: what's NOS got to do with it? Acta Physiol Scand 2003;179:123-35.
Osborne MG, Coderre TJ. Effects of intrathecal administration of nitric oxide synthase inhibitors on carrageenan-induced thermal hyperalgesia. Br J Pharmacol 1999;126:1840-6.

Ren K, Hylden JL, Williams GM, Ruda MA, Dubner R. The effects of a non-competitive NMDA receptor antagonist, MK-801, on behavioural hyperalgesia and dorsal horn neuronal activity in rats with unilateral inflammation. Pain 1992;50:331-44.

Ruscheweyh R, Goralczyk A, Wunderbaldinger G, Schober A, Sandkühler J. Possible sources and sites of action of the nitric oxide involved in synaptic plasticity at spinal lamina I projection neurons. Neuroscience 2006;141:977-88.

Schäfers M, Geis C, Svensson CI, Luo ZD, Sommer C. Selective increase of tumour necrosis factor-alpha in injured and spared myelinated primary afferents after chronic constricitve injury of rat sciatic nerve. Eur J Neurosci 2003;17:791-804.

Sekiguchi F, Mita Y, Kamanaka Y, Kawao N, Matsuya H, Taga C, et al. The potent inducible nitric oxide synthase inhibitor ONO1714 inhibits neuronal NOS and exerts antinociception in rats. Neurosci Lett 2004;365:111-5.

Semos ML, Headley PM. The role of nitric oxide in spinal nociceptive reflexes in rats with neurogenic and non-neurogenic peripheral inflammation. Neuropharmacology 1994;33:1487-97.

Stanarius A, Topel I, Schulz S, Noack H, Wolf G. Immunocytochemistry of endothelial nitric oxide synthase in the rat brain: a light and electron microscopical study using the tyramide signal amplification technique. Acta Histochem 1997;99:411-29.

Tao F, Tao YX, Mao P, Zhao C, Li D, Liaw WJ, et al. Intact carrageenan-induced thermal hyperalgesia in mice lacking inducible nitric oxide synthase. Neuroscience 2003;120:847-54.

Tao F, Tao YX, Zhao C, Doré S, Liaw WJ, Raja SN, et al. Differential roles of neuronal and endothelial nitric oxide synthases during carrageenan-induced inflammatory hyperalgesia. Neuroscience 2004;128:421-30.

Tegeder I, Costigan M, Griffin RS, Abele A, Belfer I, Schmidt H, et al. GTP cyclohydrolase and tetrahydrobiopterin regulate pain sensitivity and persistence. Nat Med 2006;12:1269-77.

Tinker AC, Beaton HC, Boughton-Smith N, Cook TR, Cooper SL, Fraser-Rae L, et al. 1,2-Dihydro-4-quinazolinamines:mpotent, highly selective inhibitors of inducible nitric oxide synthase, which show anti-inflammatory activity in vivo. $\mathrm{J}$ Med Chem 2003;46:913-6.

Tsujino H, Kondo E, Fukuoka T, Dai Y, Tokunaga A, Miki K, et al. Activating transcription factor 3 (ATF3) induction by axotomy in sensory and motoneurons: a novel neuronal marker of nerve injury. Mol Cell Neurosci 2000;15:170-82.

Wiesenfeld-Hallin Z, Hao JX, Xu XJ, Hokfelt T. Nitric oxide mediates ongoing discharges in dorsal root ganglion cells after peripheral nerve injury. J Neurophysiol 1993;70:2350-3.

Wiencken AE, Casagrande VA. Endothelial nitric oxide synthetase (eNOS) in astrocytes: another source of nitric oxide in neocortex. Glia 1999;26:280-90.

Winer J, Jung CK, Shackel I, Williams PM. Development and validation of real-time quantitative reverse transcriptase-polymerase chain reaction for monitoring gene expression in cardiac myocytes in vitro. Anal Biochem 1999;270:41-9.

Wu J, Lin Q, Lu Y, Willis WD, Westlund KN. Changes in nitric oxide isoforms in the spinal cord of rat following induction of chronic arthritis. Exp Brain Res 1998;118:457-68. 